\begin{tabular}{|c|c|c|c|c|c|}
\hline MUNIBE Antropologia-Arkeologia & $n^{\circ} 69$ & $283-296$ & DONOSTIA & 2018 & ISSN 1132-2217 • eISSN 2172-4555 \\
\hline
\end{tabular}

\title{
La ambivalencia del paisaje: de la genealogía a la arqueología agraria
}

\author{
The ambiguity of the landscape: \\ from a genealogy towards an agrarian archaeology
}

PALABRAS CLAVES: Arqueología; paisaje; patrimonio; arqueología agraria; comunidad.

GAKO-HITZAK: arkeologia; paisaia; ondarea; nekazaritzako arkeologia; komunitatea.

KEY WORDS: Archaeology; landscape; heritage; agrarian archaeology; community.

Pablo ALONSO GONZÁLEZ(1), Margarita FERNÁNDEZ MIER(2) y Jesús FERNÁNDEZ FERNÁNDEZ(3)

\section{RESUMEN}

En el mundo clásico y medieval, tanto mediterráneo como germánico, el paisaje se refería a las relaciones inmanentes entre grupos humanos, sus territorios y las formas de estructurar estas relaciones. Con la ruptura que supone la modernidad y el pensamiento abstracto renacentista y científico, surge la dualidad del paisaje; por un lado como realidad, por otro como la representación que de esa misma realidad se hace un sujeto ajeno a ella. Pretendemos conectar esta genealogía del paisaje con la práctica arqueológica contemporánea, reclamando una noción de paisaje relacional, que nos permita realizar intervenciones más allá de la arqueología, pero desde ella, es decir, intervenciones indisciplinadas. Reflexionamos sobre el trabajo del grupo de investigación en Arqueología Agraria en Asturias (España), un ámbito dominado cada vez más por la práctica disciplinar no reflexiva y una escasa preocupación por la percepción social de la arqueología y su potencial político. En este contexto, reclamamos una arqueología social que se apropie del concepto de paisaje. Pero esto no implica abandonar las prácticas arqueológicas disciplinares, ya que éstas, a su vez, están amenazadas por la liberalización de la academia y el ocaso de la arqueología de contrato.

\section{LABURPENA}

Mundu klasikoan eta Erdi Arokoan, Mediterraneokoan zein germanikoan, paisaia giza taldeen, lurraldeen eta harreman horiek egituratzeko moduen arteko lotura immanenteei lotuta zegoen. Modernitateak eta pentsamendu abstraktu errenazentistak eta zientifikoak eragindako hausturaren ondorioz, paisaiaren dualtasuna sortzen da; alde batetik, errealitate gisa eta bestetik errealitate hori oinarritzat hartuta, bertatik kanpo dagoen subjektuaren adierazpen gisa. Gure helburua da paisaiaren genealogia hori lan arkeologiko garaikidearekin lotzea, harremanen paisaiaren nozioa aldarrikatuta. Horri esker, arkeologiaz harago joanda, baina aldi berean bertatik abiatuta, esku-hartzeak egin ahal izango ditugu; hau da, diziplinarik gabeak. Asturiaseko (Espainia) Nekazaritzako arkeologiako taldeko lanaren inguruko gogoeta egin dugu. Esparru horretan gero eta gehiago dira nagusi gogoetarakoa ez den diziplinako jardunbidea eta arkeologiaren eta haren potentzial politikoaren iritzi sozialarekiko kezka txikia. Testuinguru horren baitan, paisaiaren kontzeptua bere egingo duen arkeologia soziala eskatu nahi dugu. Horrek, ordea, ez du esan nahi diziplina mailako jarduera arkeologikoak albo batera utzi behar ditugunik; izan ere, horiek, aldi berean, akademiaren liberalizazioaren eta kontratuko arkeologiaren gainbeheraren arriskua bizi dute.

\section{ABSTRACT}

In the classic and medieval European times, both Mediterranean and Germanic, landscape referred to the immanent relationships between and among human groups, their territories and the ways of structuring these relationships. With the break entailed by modernity and the abstract and scientific thought harboured by the Renaissance, the landscape concept is split into two. On one side, it is conceived as 'reality' as such, on the other, as the representation of that same reality estranged from subjective experience. This paper connects a genealogy of the landscape concept with contemporary archaeological practice. It reclaims a relational notion of landscape, one which allows us to go beyond archaeology but starting from archaeology: that is, undisciplinary interventions in the sociopolitical sphere. To do so, we reflect on our research group Agrarian Archaeology in the area of Asturias (Spain), a context dominated by nonreflexive disciplinary practice and little interest on the social perception of archaeology and its political potential. By claiming a social archaeology that reclaims the concept of landscape, we do not argue for an abandonment of disciplinary archaeological practices, as these are, in turn, threatened by the liberalization of academia and the decline of contract archaeology.

\footnotetext{
(1) Incipit-CSIC, Avenida de Vigo s/n, Santiago de Compostela, España. Pabloag10@hotmail.com

(2) Universidad de Oviedo, Calle San Francisco, España. Margarita.mier@unileon.es

(3) UCL Institute of Archaeology, 31-34 Gordon Square - London, United Kingdom. j.fernandez-fernandez@ucl.ac.uk
} 
Este artículo traza la relación entre paisaje y arqueología desde una perspectiva genealógica y política, presentando el trabajo del grupo de investigación en Arqueología Agraria en Asturias, España. Es bien conocida la ambivalencia de la noción de paisaje (Bender 2006), que ha pasado de referirse a un conjunto de relaciones entre un territorio y sus gentes en el mundo clásico y medieval, a una representación subjetiva de ese mismo territorio desde el Renacimiento. Esta dualidad tiene consecuencias importantes para las distintas formas de concebir el paisaje y para la arqueología como ciencia social. No sólo por cuestiones éticas e ideológicas, sino de propia supervivencia disciplinar en un contexto de crisis económica y liberalización generalizada, los arqueólogos no pueden dar la espalda a las personas con las que trabajan, para las que producen conocimiento, y a las que disturban o incomodan con sus prácticas. En el caso español, esto requiere una reflexión sobre las poblaciones de las zonas rurales en las que se realiza mayoritariamente el trabajo arqueológico, y sobre las políticas desarrollistas y postindustrialistas que se implementan en sus territorios. Ante la falta de competitividad del sector agrícola europeo, estos programas, principalmente aquellos relacionados con la PAC, tanto las subvenciones a la producción como los programas de Desarrollo Rural, promueven una transición postindustrialista del territorio, y la conversión de campesinos en emprendedores (Alonso González 2014b). Así, uno de los rasgos definitorios del ámbito rural como era la relación entre comunidad, territorio y producción, deja paso de forma acelerada al consumo como factor dominante (Cosgrove 2006). Este artículo se pregunta sobre el papel de la arqueología en esta transición, sobre cómo establecer relaciones más simétricas con las personas con las que trabaja, y de qué forma pueden ser útiles sus reconstrucciones del pasado para los grupos sociales subalternizados en el presente.

El artículo traza una genealogía de las distintas nociones de paisaje que subyacen a las políticas implementadas en el campo, y de la propia dificultad del concepto de paisaje para dar cuenta de cuestiones de ideología y relaciones de poder (Daniels 2014). Para ello reflexiona acerca de arqueologías del paisaje tanto 'románticas' como 'ilustradas', las unas enfatizando una perspectiva fenomenológica y subjetiva acerca de la experiencia individual en el paisaje-más concernidas con el lugar-, las otras cartografiando, analizando y representando la realidad desde una perspectiva urbana, abstracta y universalista de la ciencia-más concernidas con el espacio (Gosden y Head 1994). Por mucho que se enfatice el carácter social del paisaje (Criado-Boado 2001), la arqueología no ha hecho más que profundizar la generación de alocronía con respecto a su objeto de estudio en su fijación cada vez más generalizada por la producción de datos y certezas desde la revolución procesualista (Fabian 2002, Alonso González 2016). La arqueología del paisaje ha tendido a concebir su objeto de estudio y a las personas (campesinos, indígenas, etc.) como 'otros' automáticamente preterizados, subalternizados, naturalizando la ruptura y discontinuidad entre pasado y presente (Londoño 2013). A la vez, paradójicamente, se ha generalizado la proyección de ideologías presentes al pasado-presentismo-, haciendo que en muchas interpretaciones arqueológicas los actores del pasado se parezcan más a individuos emprendedores que a campesinos contemporáneos.

Deconstruir la ruptura entre presente y pasado equivale a poner sobre la mesa la crisis del objetivismo y de la representación a partir de una autocrítica que nos impida reproducir las mismas lógicas. Lo cual no conlleva, como una crítica superficial pretendería, el abandono disciplinar y el fin de la autoridad epistémica de la arqueología, sino su relativización dentro del conjunto de realidades que habitan el mundo. Implica también mostrar que la autoridad epistémica de la arqueología ha de ser construida socialmente con las personas y hacia el público, más allá de su pretendido universalismo que no es más que un parroquialismo construido dentro de los muros de la academia (Gnecco 2005, 184). La arqueología del paisaje ha de producir datos sólidos, y mostrar que sabe producirlos e interpretarlos mejor que otras arqueologías deudoras de los meros estudios descriptivos y con interpretaciones externas a los conocimientos de las comunidades, como ha venido reivindicando la arqueología postprocesual (Alonso González 2012), además de darle usos sociales. De hecho, la crítica posmoderna y algunas autocríticas decoloniales a la epistemología de la arqueología resultan políticamente autodestructivas al considerar que la noción de que la arqueología nos proporciona acceso al pasado es un constructo ideológico (Bender 2006), o que cualquier tipo de ciencia es automáticamente colonial independientemente de los posicionamientos políticos que defienda (Lahiri et al. 2007, 11). Estas autocríticas resultan paradójicas, ya que, por un lado, denuncian y evidencian las relaciones de dominación en el pasado y en el presente a través del método científico, a la vez que reniegan de la veracidad de ese mismo método. Creemos necesario, entonces, un análisis histórico crítico que demuestre la existencia de relaciones de explotación y las desigualdades del mundo, no sólo de forma simbólica o discursiva, sino real.

La relación de esta genealogía con la arqueología del paisaje nos lleva a plantear que, desde nuestro punto de vista, aquella debería devenir una arqueología agraria, es decir, una arqueología que vincule los procesos productivos a lo largo de la historia con los problemas presentes. Esto nos permite comprender las luchas por el territorio rural entre campesinado y elites en el territorio español como conflictos de larga duración que se prolongan hasta la actualidad, con un importante protagonismo del campesinado en la toma de decisiones productivas y en el establecimiento de estrategias de defensa de su territorio. Esto resulta fundamental a la hora de comprender grupos 
sociales contemporáneos que aún preservan formas de producir derivados de tendencias históricas y que han logrado ser resilientes frente al racionalismo capitalista. Uno de los mejores ejemplos es la gestión de las áreas de pasto y bosque que, en algunas zonas, han logrado mantenerse en manos de las comunidades locales; bajo un sinfín de modalidades de propiedad y gestión, son el reflejo de la constante lucha del campesinado por preservar en su seno no sólo su aprovechamiento, sino también su propiedad, ya que resultaban imprescindibles para la manutención de la cabaña ganadera y para la obtención de otros recursos. Estos espacios de gestión comunal sufrieron la presión de distintos grupos a lo largo de la historia: los señores feudales (monasterios o grandes propietarios laicos), burguesía rural y estado liberal (Fernández Mier et al. 2013). Proceso que se refleja en las desamortizaciones del siglo XIX (Lana Berasain 2008), y más recientemente de las nuevas políticas neoliberales con la Ley de Racionalización y Sostenibilidad de la Administración Local, o Ley Montoro que limita considerablemente el papel de las entidades menores en la gestión de un amplio patrimonio comunal (Alonso González 2017).

Planteamos pues este artículo como una síntesis reflexiva del trabajo sociopolítico 'indisciplinario' (Haber 2011), 'por fuera y alrededor' de la disciplina, que ha llevado a cabo el grupo de investigación desde 1995 en el noroeste de la península, posteriormente denominado como Arqueología Agraria. Esta es una reflexión necesaria en el contexto español, donde las relaciones entre arqueología, territorio y comunidades son raramente discutidas, con algunas excepciones como los congresos internacionales de Socialización del Patrimonio en el Medio Rural, y algunos ejemplos aislados con las comunidades (Ayán Vila y Gago Mariño 2012) (Ruiz-Ruiz y Civantos 2017). Paradójicamente, desde España se trabaja con las comunidades cuando se implementan políticas de cooperación al desarrollo en segundos países, pero resultan muy desiguales las relaciones que se han articulado con estos grupos desde las distintas Comunidades Autónomas. En casos como el de Asturias, su implicación en las políticas de desarrollo rural es meramente nominal, siempre a través de la participación de sindicatos y asociaciones en las juntas directivas de los grupos de desarrollo rural, mayoritariamente regidos por la clase política (Alonso González y Macías Vázquez, 2014b). Todo ello a pesar de existir un campesinado que sigue utilizando sistemas de gestión tradicional del territorio - a diferencia del campesinado del resto de Europa que ya participa de una agricultura capitalista - cuya colaboración activa en las políticas de desarrollo rural sería un pilar fundamental (Izquierdo Vallina 2008). Esto contrasta con la situación sudamericana donde, ya en 2003, Chungara editaba un número problematizando la relación entre patrimonio, comunidad y academia, discusión que se ha venido intensificando con el tiempo (Ayala et al. 2003, Angelo 2010).

\section{LA IDEA DE PAISAJE}

Pese a resultar imposible desarrollar una genealogía completa de la idea de paisaje, y no es nuestro interés central aquí, creemos importante contextualizar esta noción en un marco genealógico que nos permita conocer su evolución en Occidente en momentos históricos clave. En su historia de la 'idea de paisaje', Cosgrove (2006) la concibe como una forma moderna de relacionarse y representar el mundo exterior de forma gráfica y espacial que implica una relación entre individuo y comunidad. El paisaje no es entonces únicamente un instrumento hegemónico de dominación, y su propia evolución semántica más bien refleja la evolución sociocultural de los grupos humanos en la modernidad. Desde una perspectiva antropológica simétrica, es importante subrayar la imposibilidad de separar paisaje y paisanaje en ámbitos aislados; es decir, el paisaje no existiría sin el paisanaje y viceversa: se trata de un conjunto de relaciones o replicaciones estructurales de normas y conductas generadoras de mundo. De hecho, la raíz etimológica de la palabra paisano_-habitualmente equiparado a campesino-deriva del latín en las lenguas romances-paesano, pagés, paysan-, y de las formas pagense y ager pagense, relacionadas con el ager, el campo que rodeaba al pago o villa (Izquierdo Vallina 2008,81 ). No es casualidad que ya los primeros grandes intentos cartográficos de dominar el paisaje fueran realizados en tiempos clásicos por agrimensores romanos (Gil, Esparraguera, y Martínez 2004).

Paisano prevaleció sobre pagano, el habitante del pagus resistente al cambio y a la imposición de las creencias y tradiciones cristianas. El país es el lugar, el pagus es donde el pagano construyó sus paisajes agrícolas. Esta etimología y la asociación entre paisano y pagano en el mundo clásico apunta a un potencial de resiliencia y rechazo a las imposiciones externas por parte de las comunidades. Igualmente, el término paisaje deriva del pagus latino, mientras las lenguas germánicas parten del original land para derivar en landschaft, landscape o landschape, con un sentido semejante: un territorio productivo y sus gentes (Maderuelo 2006). Vale la pena detenerse en el significado del concepto 'paisaje' en el ámbito germánico-escandinavo durante el Medievo, ya que ilustra la imbricación indisociable entre territorio y personas que reclamamos. Según Olwig (2002), Landschaft se aplicaba en el Medievo sólo a territorios específicos del Mar del Norte y el Báltico. Resulta especialmente significativo que su denominación como paisajes iba estrechamente vinculada al hecho de que en estas áreas imperaba el derecho consuetudinario y el régimen colectivo de la tierra, que a la vez definía los límites y funcionamiento del propio territorio (Land). Es decir, "costumbre y cultura definían un Land, no las características físicas o geográficasse trataba de una entidad social que encontraba su expresión física en el área bajo su legislación" (Olwig 2002, 17). Las distintas combinaciones entre costumbre, comunidad y aprovechamiento productivo del terri- 
torio producían diferencias morfológicas objetivas entre los distintos Landschaften, que podían ser percibidas por los individuos de forma subjetiva. Es decir, existía una inmanencia relacional entre visión y territorio que resultaba de prácticas cotidianas y de producción, sin los aspectos estéticos y escénicos que surgirán con la ruptura moderna. Será Alexander von Humboldt quien, siglos más tarde, transformará el concepto de Landschaft tradicional en una noción científica social, de nuevo con todas sus ambivalencias, ya que se refería a la vez a la realidad de un territorio y a su representación figurativa.

Durante el Medievo el paisaje va a seguir designando un espacio productivo y a sus gentes también en el sur de Europa y otras zonas. En Inglaterra, por ejemplo, el término landscipe se refería a un distrito propiedad de lo explotado por un señor y habitado por personas (English y Mayfield 1972, 10). Pero ya en el bajo Medievo es posible percibir una tensión, y el comienzo de la disgregación entre la vida y la representación, el espacio vivido del visto, el productivo del estético (Bote 2014). Este proceso coincide con el auge del aristotelismo y el gótico, y con la expansión del intercambio mercantil en centros urbanos que lleva al surgimiento de habitantes del burgo o burgueses, distanciados empíricamente del campo y sus cualidades estéticas.

Desde una perspectiva dialéctica, entonces, la ambivalencia del paisaje nace de relaciones sociales reales y es consecuencia de las mismas, y no producto de transformaciones en los ámbitos artísticos o culturales desligados de la sociedad. Aislar el concepto de paisaje de las relaciones sociales nos puede llevar a debates tautológicos y universalizantes sobre el paisaje. Por ejemplo, de Pisón Stampa $(2002,13)$ afirma que el paisaje es un 'fenómeno cultural' basado en la relación de un observador con su entorno, y que la capacidad humana de reconocimiento estético del paisaje sería 'universal'. Por contra, Maderuelo (2006, 31) niega que actores como ganaderos o agricultores sean capaces de discernir o ver un paisaje. Como muestra Latour (2008), ambas visiones serían extremadamente asimétricas: presuponen la existencia del paisaje, y a partir de ahí analizan si cierto individuo, grupo o clase, es capaz de 'verlo' o no a partir de prejuicios teóricos.

Ante este impasse, Cosgrove (1985) insiste en que la noción de paisaje como representación nace con el Renacimiento en los siglos XV y XVI. Vincula esta transformación con la epistemología de la ciencia moderna y la emergencia del capitalismo. El pensamiento abstracto moderno rompe con la pintura paisajística medieval, plasmación del orden divino en la naturaleza, donde no existía una separación entre ser humano y naturaleza ni una perspectiva lineal que permitiese representar el mundo con exactitud. Al contrario, la pintura renacentista paisajística sitúa al observador fuera del cuadro. A ello contribuye la adopción de la perspectiva caballera y lineal, que hace primar la mirada del sujeto que observa y la visión del ojo, al permitir situar al observador en un espacio geográfico determinado (Baxandall 1988).
Esta voluntad de conocer todo en su justa proporción va vinculada a la explotación del territorio, como queda patente en De re aedificatoria, donde Alberti escribe en 1450:

Mediante el corte de las rocas, la perforación de las montañas, la nivelación de los valles, la contención de las aguas marinas y lacustres, el vaciado de los pantanos, la construcción de las naves, la rectificación del curso de los ríos, la excavación de desagües para las aguas, la construcción de puentes y de puertas [el artífice] no solo resuelve problemas de orden temporal, sino que abre el camino hacia todas las regiones de la tierra. De esta manera, los distintos pueblos podrán participar mutuamente de todo cuanto conviene a la mejora de la calidad de vida: productos agrícolas, piedras preciosas, experiencias y conocimientos. (citado en Tafuri 1995, 74-75).

La cita muestra la doble voluntad de representación, explotación y mercantilización que ya se vislumbraba en los inicios del Renacimiento italiano (Durán 2008). Estas transformaciones no se pueden desvincular del auge de una parte de las burguesías mercantilistas urbanas (las más pudientes y desvinculadas de la tierra, ya que la pequeña burguesía invertía en propiedades agrarias), que, al contrario que los señores feudales, no ven el campo en términos productivos sino estéticos y de consumo (Garo 2013). La concepción neutral y científica de la naturaleza y el mundo moderna hace pasar al paisaje a formar parte del engranaje biopolítico que los estados ponen en marcha para controlar a la población: los mayores desarrollos en pintura, geometría y matemática se dan en Italia y Países Bajos, donde ciudades dominadas por mercaderes como Ámsterdam o Venecia compiten por organizar sus territorios y negocios ultramarinos, contratando artistas para que realicen las primeras cartografías exactas. Así se amplía la brecha en la dualidad del paisaje, entre realidad y representación, entre percepción subjetiva y experiencial y su función hegemónica y de dominación. Pero ambas se imbrican, por ejemplo, en la pintura. Como han mostrado historiadores del arte y geógrafos, la pintura paisajista tendía a naturalizar desigualdades socioeconómicas a través de estéticas productoras de armonía visual y orden, que escondían las relaciones sociales de explotación que comenzaban a imperar, por ejemplo, en la Inglaterra protocapitalista del siglo XVII (Barrell 1980). Esto se manifiesta en un influyente texto de 1712, On the pleasures of the imagination, donde Joseph Addison escribía:

Un hombre de imaginación educada encuentra una mayor satisfacción que aquel otro vulgar. Puede conversar con un cuadro y encontrar en una estatua una agradable compañía [...] y a menudo siente una satisfacción más grata en la perspectiva que abren los campos y las praderas que en la que ofrece poseerlos [...] mira al mundo, por así decirlo, bajo una luz diferente, y descubre en él una cantidad de encantos que se le ocultan a la mayoría de la humanidad. (1958[1712], 278). 
Como muestra Dematteis (1985), la ambivalencia del paisaje se mantuvo entre los siglos XVII y XIX, en un precario equilibrio entre la voluntad objetivista de la ciencia, las necesidades de los estados y el surgimiento del romanticismo como reacción a ambas tendencias. Hay que tener en cuenta que los nacionalismos burgueses del siglo XIX van estrechamente asociados al romanticismo, que vinculó indisociablemente la nación a la idea de un paisaje especial y prístino, en el que los individuos, lenguajes, tradiciones y naturaleza convergían de forma orgánica. La arqueología nació de ambos impulsos modernos contradictorios: la búsqueda ilustrada de explicar el pasado científicamente, y la voluntad romántica de conocer y exaltar las historias y costumbres de los pueblos nacionales (Diaz-Andreu y Champion 1996). Al vincular política y moral, ciencia y estética, la adaptación de la noción de paisaje a las disciplinas sociales y a la gestión política burguesa no hizo más que mantener y potenciar su ambivalencia.

\section{EXPLOTACIÓN DEL TERRITORIO, PATRIMO- NIALIZACIÓN DEL PAISAJE}

Sin hacer un balance exhaustivo de la complejidad del siglo XX, cabe destacar la persistencia del dualismo paisajístico tanto a nivel académico como de gestión estatal. Por ejemplo, a comienzos del siglo XX se produjo un "giro cartográfico-descriptivo" derivado de las necesidades bélicas de los estados, que convertía al paisaje en un conjunto de objetos, con especial desarrollo en Alemania y la Unión Soviética (Ignateva 2001). A la vez, sin embargo, se reintrodujeron los valores existenciales en el paisaje y nociones identitarias con la revolución de los estudios del paisaje en Estados Unidos y Reino Unido (Sauer 1925). En los años 60 el paisaje se integró en la teoría de sistemas, mientras por otro lado se abrió a la fenomenología Heideggeriana en los trabajos de Berque (1997). Éste colocaba en el centro de su ontología al sujeto, concibiendo el paisaje como una experiencia humana subjetiva más que una parte del mundo objetivo. Estos desarrollos están relacionados con el surgimiento de la arqueología espacial asociada al paradigma procesualista (Clarke 1977), y de la arqueología del paisaje fenomenológica postprocesualistas (Tilley 1994). Pero la arqueología siguió nadando entre dos aguas respecto a la ambivalencia del paisaje. Para Ingold (1993), el paisaje sería tanto la tierra que puede contemplarse desde un mirador como lo que se representa como tal, y para Lemaire (1997) incluiría tanto la experiencia del mismo como su representación y la combinación de ambas.

A partir de los 90 se produce una eclosión de trabajos desde posicionamientos muy diversos influidos por las tesis ecologistas. En el ámbito anglosajón se desarrolla la Ennvironmental archaeology (Butzer, 1982) en el marco de las derivaciones de la arqueología postprocesual que pone su interés en los ecofactos y en el medio que condiciona el desarrollo de la vida del hom- bre. En Francia, de la convergencia de la ecología histórica de Bertrand y la tradicional historia rural surgirá la ecología histórica, que influida por la fenomenología existencial focaliza su atención en las formas visibles del paisaje, que derivará en la Arqueogeografía (Chouquer 2000) y la Arqueología Agraria (Guilaine 1991) en la que confluyen la metodología arqueológica con las ciencias naturales, que tendrá un considerable impacto en la arqueología española.

Pese a que la Nueva Geografía Cultural realizó una crítica fortísima al paisaje desde el marxismo, denunciándolo como una 'ideología visual' y una 'forma de ver' que sirve para mistificar el territorio y ofrecer una visión elitista del mismo (Cosgrove 1985), ésta es la mirada que siguen promoviendo las instituciones, especialmente desde la eclosión de la industria del patrimonio (Lowenthal 1986). Así, a pesar de los avances de la 'vanguardia académica', se mantiene una separación clara entre dos concepciones del paisaje: la cartográfica y espacial de estados e instituciones, que buscan representar y evaluar las propiedades del paisaje de forma objetiva; y la experiencial y subjetivista, que busca comprender las distintas percepciones del paisaje y su papel en la sociedad contemporánea.

Aproximándonos a nuestro caso de estudio, la persistencia de la ambivalencia del paisaje se evidencia en las contradicciones existentes entre las distintas políticas que afectan a los territorios rurales españoles y europeos: mientras las políticas desarrollistas promueven la transformación y racionalización del campo, las patrimonialistas fomentan su inmovilismo, mistificación y estetización (Cruickshank 2009). Existe así una vinculación clara entre las políticas desarrollistas y la mirada cartográfica, por un lado, y la visión subjetivista y patrimonialista propia del mundo postindustrial (Alonso González 2017).

Paradoja ligada a las transformaciones en los vectores de valorización y rentabilidad del campo: el industrialismo agrario busca explotar los recursos materiales y la tierra, mientras el postindustrialismo favorece la comercialización de productos culturales, identidades y servicios turísticos (Alonso González 2014b). La Política Agrícola Común (PAC) es el exponente máximo del industrialismo rural. Nacida en los 60, la PAC representa un tercio del presupuesto de la Unión Europea, con el objetivo de modernizar e intensificar la producción agropecuaria. La PAC ha llevado a la concentración de la propiedad de la tierra, la despoblación del campo y la destrucción de ecosistemas (Van der Ploeg 2008). Ante estos problemas, la PAC reorientó su discurso en los 2000 hacia la 'protección paisajística' a través de su política de Desarrollo Rural (11\% del presupuesto UE). Esta política pretende transformar al agricultor en 'defensor del paisaje' y diversificar las economías rurales. En la práctica, esto ha llevado al establecimiento de estructuras de gobernanza neoliberal como los LEADER, proyectos de desarrollo gestionados por grupos de acción local no elegidos democráticamente, sino de 
forma tecnocrática, que promueven la figura del 'emprendedor rural' y la transición a economías postindustriales (Alonso González, Macías Vázquez, 2014b).

Ante el desarrollismo de la PAC, otros actores europeos han promovido la patrimonialización del paisaje, en línea con las clasificaciones patrimoniales nacionales y globales. En este sentido, la UNESCO en el Comité de Patrimonio Mundial en Santa Fé, Nuevo México en 1992 aprobó el concepto de paisaje cultural que privilegia una visión representacional y estetizante del paisaje, además de reproducir la dicotomía naturaleza/ cultura en su categoría de 'paisaje cultural', concebido como un ente estable carente de historicidad y dinamismo(Alonso González 2013b). Generalmente, interesa la preservación a toda costa del paisaje y, más profundamente, de sus cualidades estéticas; evaluaciones realizadas en base a supuestos históricamente construidos por la modernidad occidental sobre qué representa lo bello y lo bueno (Alonso González y Macías Vázquez 2014a). Más ambiciosa que la UNESCO es la Carta Europea del Paisaje de Florencia del año 2000 (CEP), que pretende proteger todos los paisajes europeos por sus valores patrimoniales, identitarios y ecológicos, definiendo el paisaje como un área resultado de la interacción entre factores humanos y naturales.

Tanto la PAC como la CEP promueven y reflejan una transición en la gobernabilidad y en la concepción del 'recurso territorial' del campo. En sociedades postindustriales, el potencial de valorización del campo reside no tanto en la producción de bienes tangibles sino en el potencial de consumo de bienes culturales en el marco de una sociedad ligada a valores postmaterialistas (Inglehart 2006). En ella, tradiciones, identidades y culturas son cosificadas como patrimonio demandado por los turistas y otros actores económicos y extraeconómicos, como promotores inmobiliarios, arquitectos paisajistas, empresas de museología y ocio, etc.

Así, el dinero público se dirige a financiar actividades no rentables y no productivas-preservación patrimonial y paisajística o museos-y a subvencionar las actividades rentables y productivas de emprendedores privados, generalmente en el sector turístico, hotelero o de restauración, apropiándose de los 'recursos territoriales' clave en el postindustrialismo: el 'valor común' generado por las comunidades, sus tradiciones, cultura material y paisaje (Alonso González 2014a).

Para nosotros, el paisaje ha de ser concebido como un producto, el resultado histórico de la relación intrínseca entre un grupo humano y un área, y de la gestión colectiva de los recursos en base a unas normas. Partiendo de la concepción del Landschaft germano, consideramos que el paisaje es un conjunto de relaciones inmanente, generado a través de las actividades de las personas y sus sentimientos, planes y vinculaciones desarrolladas con emplazamientos y acontecimientos específicos que conforman su identidad. Por tanto, la gestión del territorio tanto de raigambre ilustrada como romántica, desarrollista y postdesarrollista, no ha hecho más que minar las bases del propio valor paisajístico en sus dos vertientes: destrucción de lo natural por el industrialismo, cosificación de lo social como patrimonio por el postindustrialismo. Esto nos permite entender que el paisaje en el postindustrialismo no es sólo un bien a consumir por clases medias urbanas, sino una realidad que requiere un proceso productivo detrás. Lo cual no implica un retorno idílico a comunidades locales aisladas, ni a una idea romántica de un campesinado productivista, hoy imposible de sostener. Pero sí implica establecer una correspondencia entre nuestro trabajo académico y las comunidades que estudiamos, teniendo en cuenta que el paisaje hoy día no es sólo producto de la comunidad local, sino de relaciones más amplias a distintas escalas cuya transformación requiere otro tipo de estrategias más allá de la 'arqueología comunitaria' o la 'arqueología pública'; es decir, la legitimación del trabajo académico ante la comunidad, o la educación de la misma en el 'patrimonio', perspectivas ambas ampliamente paternalistas, asimétricas, que han de ser superadas.

\section{ARQUEOLOGÍA AGRARIA EN ASTURIAS}

La arqueología española ha jugado un papel ambiguo en relación a las políticas de desarrollo rural. La arqueología comercial se ha expandido durante décadas gracias a su vinculación a la construcción de infraestructuras rurales, ofreciendo una compensación simbólica por la destrucción generalizada del campo, preservando de la destrucción espacios y sitios de interés-para las elites urbanas_, y promoviendo su transformación en patrimonio (Marín Suárez y Parga Dans 2017). En la arqueología académica, en cambio, se percibe una deriva reflejada en los propios nombres y proyectos de los grupos de investigación hacia nociones primero de paisaje, y más recientemente de patrimonio ${ }^{1}$. La legitimidad de la producción académica se asienta así tanto en la producción de 'ciencia', como en la defensa y promoción de las identidades nacionales y regionales que el discurso patrimonial legitima (Alonso González 2017). Nosotros concebimos la investigación arqueológica como una práctica científica social situada en el contexto político y económico que la condiciona, pero con potencial transformador. Nuestros trabajos buscan conectar pasado y presente en dos ámbitos. El primero busca producir discursos históricos alternativos que pongan en duda las narrativas dominantes, tanto de los regionalismos identitarios como de las políticas de gestión del territorio, y difundirlos a través de la arqueología pública y de comuni-

\footnotetext{
${ }^{1}$ Grupos de investigación en Patrimonio Cultural en España: http://www.iaph.es/phinvestigacion/pdf/Gruposdeinvestigacion.pdf
} 
dad. El segundo, pretende promover formas de gestión patrimonial alternativas en la práctica y en la teoría a nivel local y regional (Alonso González y Fernández Fernández 2013). [Figura 1]

Nuestro trabajo se centra en las regiones de León y, sobre todo, Asturias. Asturias es una región montañosa del noroeste ibérico. El 74\% de su millón de habitantes se concentra en un $10 \%$ del territorio, mientras las zonas rurales, donde se realiza la mayor parte del trabajo arqueológico, albergan al resto de la población, generalmente envejecida y en proceso de despoblación. El clima de crisis generalizada en la región desde los años 80 hizo que Asturias fuera incluida en los planes de convergencia europeos, que buscaban disminuir los desequilibrios económicos entre distintas regiones mediante la transición a economías postindustriales. Como resultado, en 2014 el 72\% de la población rural trabajaba ya en el sector turismo y servicios, en una región eminentemente campesina hasta tiempos recientes (SADEI 2016). El turismo comenzó a ser visto como la panacea, concentrando la inversión privada, en hoteles y restaurantes, y pública, llevando a la creación de decenas de museos hoy en estado de abandono ${ }^{2}$. Sin embargo, se prestó escasa atención a las actividades productivas del campo que permitían fijar población y preservar el paisaje asturiano, que se estaba comercializando como reclamo principal para el turismo. Más bien, se minó el derecho consuetudinario y la gestión colectiva de los recursos que imperaba - incluyendo agua, caza, ganado, cultivos, recolección, o la organización de eventos y fiestas - fragmentando a las comunidades rurales y promoviendo la industrialización de la agricultura y la ganadería (Daugstad, Mier, y Peña-Chocarro 2014).

Estos planes se reforzaban con la estrategia del gobierno regional de generar una 'marca Asturias' como 'Paraíso Natural', vinculada a su percepción como un territorio verde, húmedo y montañoso, en contraste con el paisaje español estereotipado, amarillo, seco y llano. Se crearon 5 Parques Naturales, además del Parque Nacional de la Montaña de Covadonga, la reserva de la biosfera de Muniel.los y un buen número de paisajes protegidos, estando casi un tercio de la extensión de Asturias declarado Espacio Natural Protegido3; así los 'valores naturales' y 'ecológicos' se convirtieron en ejes nodales de la promoción turística asturiana. Se construyeron centros de interpretación de lobos y osos, y se llegó a cambiar la toponimia: el valle del Trubia pasó a ser el del Oso. Esta situación dejaba los aspectos culturales y sus valores territoriales asociados en segundo plano, marginando a los actores locales e ignorando su papel en el mantenimiento de esa supuesta 'naturaleza' prístina. Los habitantes del campo asturiano no sólo no participan en la implementación y diseño de estas políticas y no se identifican con ellas, sino que más bien van en contra de sus valores e intereses: consideran lobos y osos como amenazas a su producción agropecuaria, y ven el turismo como una actividad extraña

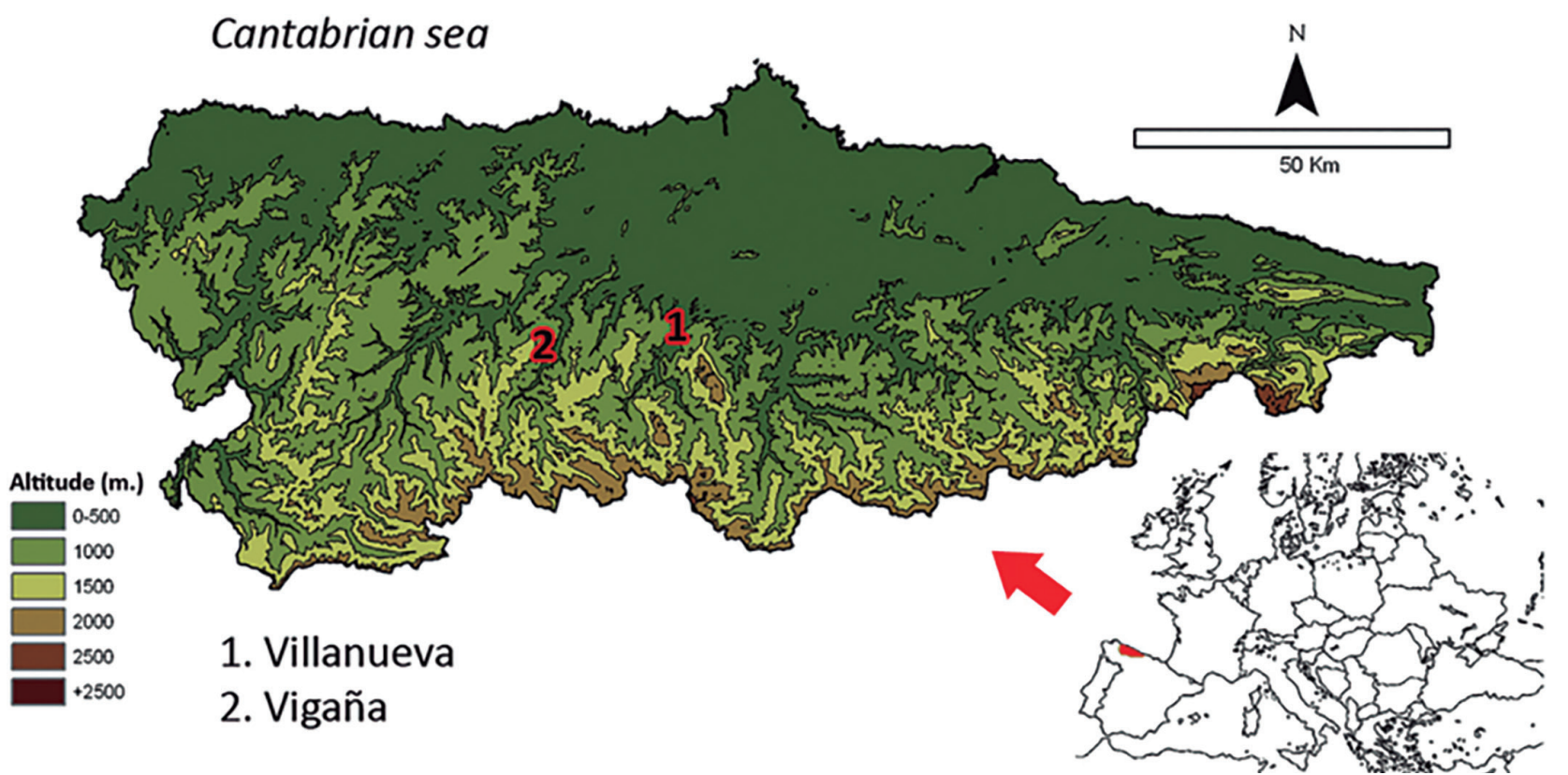

Fig. 1. Situación de las zonas de estudio de Villanueva y Vigaña en Asturias, España / Location of the study areas of Villanueva and Vigaña in Asturias, Spain.

\footnotetext{
2 En la página web Sendas Verdes se puede consultar una aproximación a algunas de las infraestructuras museísticas abandonadas y su distribución por las distintas comarcas de Asturias http://www.sendasdeasturias.com/losdespilfarrosyaabandonos.html

${ }^{3}$ Se puede consultar esta información en la página web: http://www.naturalezadeasturias.es
} 
que además suele beneficiar a empresarios foráneos (González Álvarez y Alonso González 2014)4.

Dentro del primer ámbito de trabajo, hemos buscado producir historias alternativas sobre la configuración del paisaje asturiano en perspectiva de larga duración, dando a conocer otros modelos socioculturales alternativos del pasado que divergen del paradigma dominante en la contemporaneidad, el neoliberalismo. En relación con las políticas desarrollistas que conciben al campesino como un ser atrasado que necesita 'modernización' y 'desarrollo', hemos intentado mostrar más bien la sostenibilidad de las formas de aprovechamiento de las comunidades a lo largo de los siglos en toda su complejidad. Esta perspectiva histórica va aparejada a una concepción antropológica colonialista de los habitantes del medio rural, que han sufrido una construcción histórica de diferencia que los menospreciaba como 'campesinos' premodernos y atrasados, pero cuyas identidades han pasado a ser mercantilizadas como 'recursos turísticos'; bien como 'artesanos', 'guardianes del paisaje' o 'representantes de la tradición y el folklore'. A esta visión oponemos un racionamiento de la alteridad históricamente específica de los habitantes del mundo rural, vinculado a sus modos de vida. Es decir, realizamos un primer reconocimiento simbólico y discursivo de su alteridad-algo inusual en la arqueología española-que implica representar y tener en consideración su cosmovisión mítica del espacio y el tiempo. Esto se evidencia en el documental de difusión científica Arqueología Agraria: la formación de los paisajes en el Noroeste Peninsular (Alonso González 2013a), donde aparecen los habitantes del pueblo donde excavamos hablando sobre su visión del castro de la Edad del Hierro como un lugar que oculta tesoros resguardados por seres llamados mouros, creencias animistas que generalmente han sido estudiadas desde la arqueología simplemente como un medio para localizar yacimientos arqueológicos y no como un vehículo que permite el análisis y comprensión de su cosmovisión del espacio habitado y aprovechado. Nuestro grupo de investigación ha buscado analizar estas creencias animistas de forma específica y no meramente instrumental, generando un marco reflexivo alrededor del mismo para comprender la relación de las comunidades con sus ancestros, su pasado y su entorno.

Para el mantenimiento del paisaje era fundamental el régimen de explotación consuetudinaria basada en la gestión colectiva de los recursos, cuya fragmentación a lo largo del siglo XX ha llevado al fin del paisaje como lo venimos entendiendo y a la transformación del medio ambiente-por ejemplo, con la proliferación de bosque donde antes había pasto. El uso de los recursos era relativamente sostenible si no se producían transformaciones demográficas bruscas, lo que permitía una forma de resiliencia de las comunidades frente a los intentos de apropiación de sus recursos comunes desde por lo menos el inicio del proceso de feudalización en los siglos XI-XII. Esto nos permite dar legitimidad a los reclamos de las comunidades rurales, mostrando cómo sus luchas se enmarcan en una negociación de larga duración alrededor de relaciones de poder con los grupos dominantes, y que la marginación del campo asturiano es resultado de políticas específicas y no de simple ignorancia y falta de 'espíritu de progreso' o 'emprendimiento' por parte de la población (Fernández Mier, López Gómez, y González Álvarez 2013).

Otra consecuencia del reconocimiento de la alteridad históricamente específica de estos grupos implica apoyarles en reclamos con la administración aportando legitimidad histórica.

En el caso de nuestro proyecto en Vigaña, por ejemplo, las vías de implicación con la comunidad han sido varias y han dado resultados diversos. La primera iniciativa fue la organización de actividades de divulgación como charlas, días de puertas abiertas o jornadas científicas, dando paso a la organización de mesas redondas con participación de la comunidad en la que se establecía la conexión entre las prácticas económicas del pasado, en este caso la ganadería, y las problemáticas actuales. Se buscaba lograr canales de comunicación entre los ganaderos y los técnicos especializados de las distintas administraciones. Obtuvimos respuestas dispares, de especial escepticismo por parte de algunos de los miembros de la comunidad e inmovilismo desde la administración pública. Esta actividad la compatibilizamos con la realización de talleres arqueológicos en los que se han utilizado técnicas tradicionales de construcción para evitar la pérdida de este conocimiento aún en manos de los paisanos. La activa participación de los habitantes ha permitido abrir un importante canal de co-construcción de conocimiento, evitando su alienación y la generalización de redes alternativas de pseudoarqueología, como en otros territorios (Alonso González 2016)5. A lo largo del curso 2018-2019 cola-

\footnotetext{
${ }^{4}$ Un buen ejemplo son las reivindicaciones de la plataforma "Asturias Ganadera" que se presenta como un grupo activo frente a la pasividad de políticos y sindicatos; o las reiteradas denuncias de ataques de lobos que se producen dentro del grupo de Facebook "Ganaderos del Norte". También se están poniendo en marcha iniciativas como el proyecto “¿Convivencia? Ganadería y Lobos" por parte de la Unión de pequeños agricultores y ganaderos, que evidencian el continuo conflicto entre ganadería y fauna salvaje. Como ejemplo se pueden consultar algunos artículos periodísticos donde los distintos actores ofrecen visiones contradictorias sobre los daños causados por la fauna salvaje en la cabaña ganadera en Asturias: http://fedecazacyl.es/lobo-nos-esta-abrasando-advierten-los-ganaderos-picos-asturias/; http://www.miscelaneanatural. org/proteccion-ambiental/el-problema-de-la-ganaderia-asturiana-no-son-los-danos-por-lobos.

5 La colaboración con las comunidades locales se ha ido abriendo paso en los últimos años en la práctica arqueológica, como se puede evidenciar en algunos proyectos de Galicia (Ayán Vila, Gago Mariño, 2012), las comunidades de regantes de Sierra Nevada (Ruiz-Ruiz, Martín Civantos, 2017), el yacimiento de Kelín en Caudete de las Fuentes (Quixal Santos, Mata Parreño, 2018).
} 
boraremos en el proyecto docente desarrollado por el Colegio Público de Balmonte de Miranda, en el marco del cual se realizarán pequeñas intervenciones arqueológicas en la localidad para dar un paso más con los alumnos: de "jugar" en los talleres, a hacerlos participar en la propia investigación arqueológica.

También se están dando las primeras aproximaciones para apoyar a la población en la reactivación de modelos de gestión que incrementen su autogobierno y autogestión, explorando las posibilidades que ofrece la legislación autonómica o el apoyo a la legalización de antiguos documentos de propiedades colectivas. Esto se justifica históricamente por las amplias posesiones de uso colectivo que conservan, especialmente zonas de pasto y bosque, de vital importancia (Fernández Fernández, Alonso González, y Navajas Corral 2015). La labor histórica permite analizar y localizar documentación que permita generar narrativas de legitimación tanto de la propiedad como de distintas formas de aprovechamiento de estos recursos que les permitan actuar frente a los intentos de apropiación de la administración: ayuntamientos, gobiernos locales y estado central. Es necesario reconstruir las prácticas de cooperación de las comunidades a partir de sus reminiscencias, cooptando las débiles herramientas que aún conserva la administración pública. Tenemos en cuenta la complejidad interna de las comunidades y sus tensiones internas debido a distintos intereses económicos: agricultores/ganaderos (vinculados a la tierra/ productividad), profesionales del turismo que operan a distintas escalas (vendedores de intangibles a turistas), antiguos habitantes que retornan al pueblo, neorurales, habitantes de las ciudades con segundas residencias (buscadores de ocio y recreo). Nuestro trabajo intenta conciliar los distintos intereses y sensibilidades para empoderar a la comunidad en su heterogeneidad.

Esto se relaciona con un segundo aspecto, como es la deconstrucción de la narrativa del Asturias 'Paraíso Natural', mostrando cómo el paisaje mercantilizado como natural es en realidad producto de las relaciones entre los grupos humanos y la naturaleza de forma diacrónica. Primero deconstruímos la noción imperante que vincula naturaleza a salvajismo, y a animales no domesticados como oso y lobo, para después subrayar la continuidad de prácticas ganaderas en la región al menos desde la edad del Hierro (Fernández Mier et al. 2014). Nuestra lógica es la contraria a la producción de alocronía: más bien buscamos enfatizar el establecimiento de continuidades con el pasado que rompan con conceptos como el de primitivismo, atraso o subdesarrollo, haciendo estériles los discursos modernizadores del campo. En última instancia, buscamos mostrar que la lógica identitaria de la región asturiana como 'natural' no es más que un constructo y una marca turística sin base alguna (Fernández Fernández, Alonso González, y Navajas Corral 2015). A ello no oponemos la idea de que el paisaje es cultural—como hacen la UNESCO y la CEP_-sino de que es paisaje en sí mis- mo, es decir, un resultado de relaciones inmanentes de grupos humanos con un territorio determinado. Así, no se naturaliza el 'paisaje' ni se cosifica la 'naturaleza', mostrando cómo el cambio y la dinámica son lo imperante dentro de un marco de relaciones más o menos estable. [Figura 2]

En este sentido, la indisciplina en el sentido desarrollado por Haber conjuntamente con Gnecco y Sheperd (2016) introdujo cambios en nuestra propia metodología y objetivos de investigación disciplinar. Así, mientras la arqueología de la Edad Media se enfocaba tradicionalmente al estudio de núcleos habitacionales despoblados, nuestro grupo enfatizó la importancia de investigar los pueblos actuales que todavía son habitados junto con todo el espacio productivo que los rodea (Fernández Fernández 2017). Esto implica prospectar zonas amplias y excavar terrazas agrícolas, zonas de pasto o trashumancia, o bosques, empleando metodologías múltiples y análisis palinológicos, edafológicos y radiocarbónicos, entre otros (Fernández Mier y Alonso González 2016). Esto nos permitió comprender la evolución diacrónica de los espacios productivos, evidenciando las grandes transformaciones y conflictos sociales por los recursos que se produjeron, en grandes trazos, con la feudalización entre los siglos X y XII, la llegada de cereales de América en los siglos XVI y XVII, y la mecanización del campo en el siglo XX (Fernández Mier et al. 2014). [Figura 3]

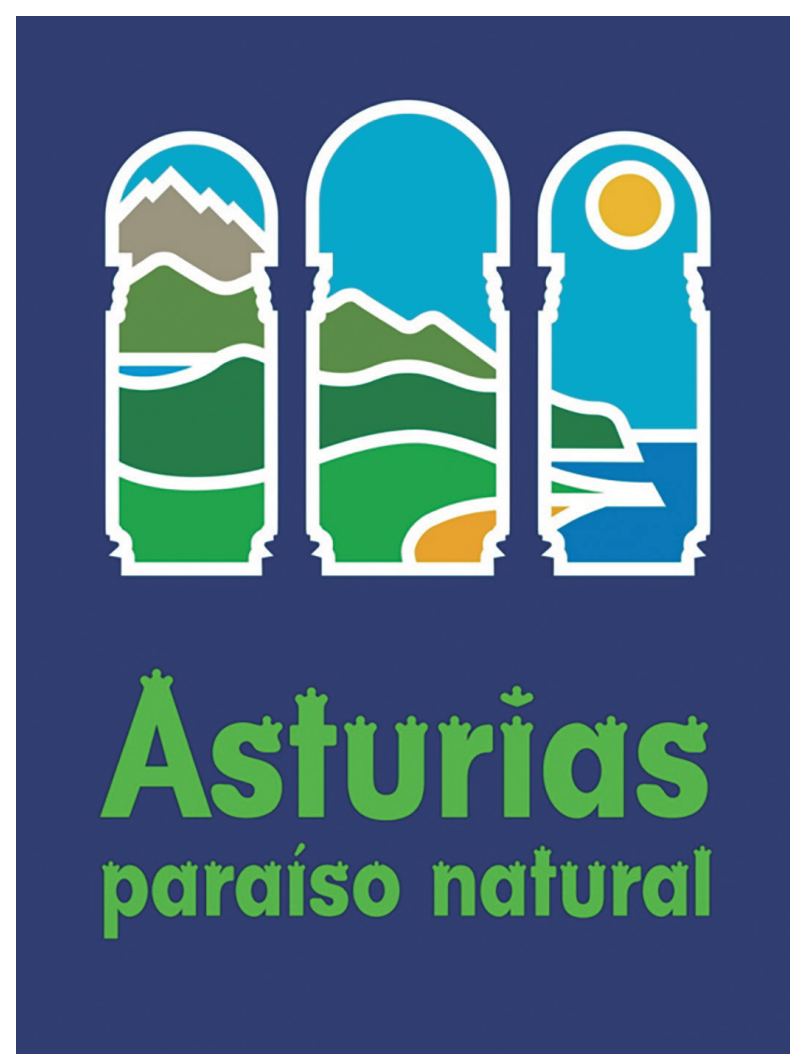

Fig. 2. Marca turística de Asturias como "paraíso natural". / Tourism trademark of Asturias as a "natural paradise". 

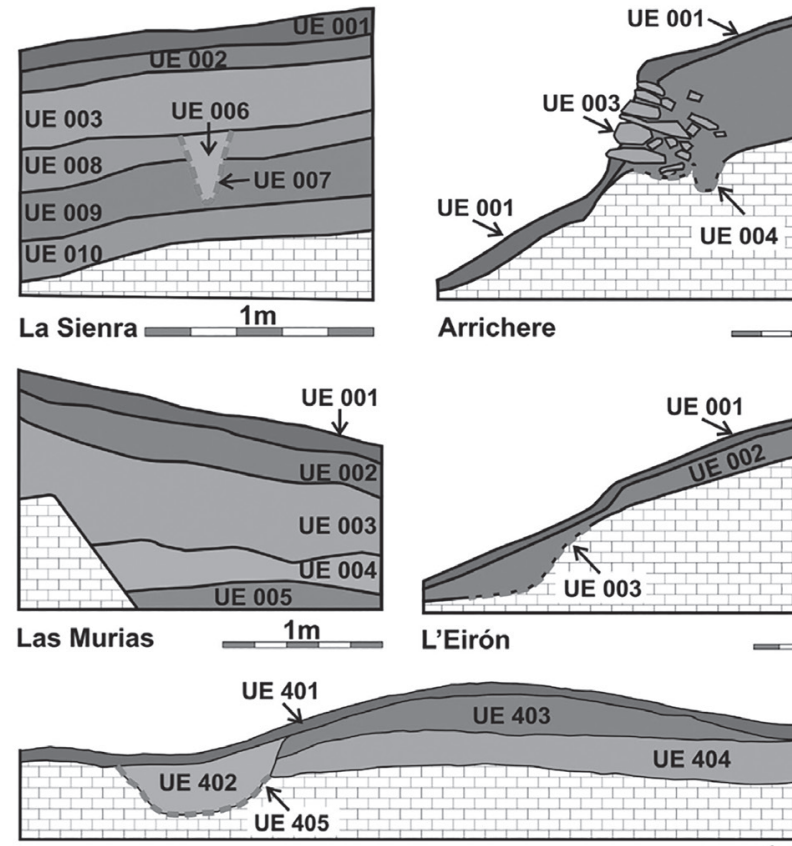

Folgueras

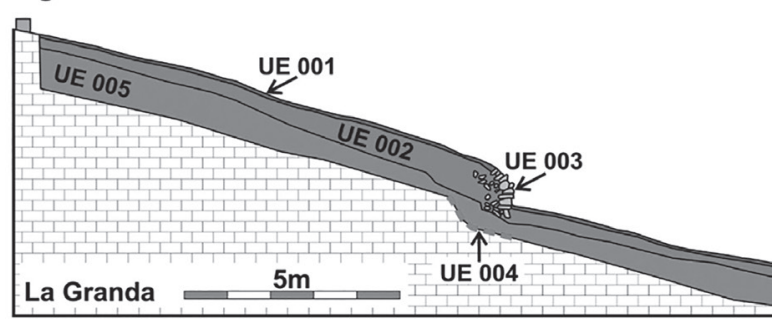

Fig. 3. Complejidad estratigráfica de varias zonas de cultivo investigadas arqueológicamente en Vigaña, que van desde cronología neolítica a subcontemporánea. / Stratigraphy of the various areas of cultivation explored through archaeological methods in Vigaña, from the Neolithic to contemporary times.

En un segundo ámbito de actuación, pretendemos ir más allá del ámbito disciplinar para transformar el contexto socioeconómico en el que se inscribe la vida de los actores con los que trabajamos, que es similar al nuestro. Nos planteamos inicialmente aplicar nuestra teorización sobre la continuidad entre la gestión de los bienes comunes materiales o tradicionales de forma colectiva en base a las leyes consuetudinarias (tierra, agua, bosque), al contexto actual postindustrial, en el que la gestión de los recursos materiales 'finitos' pierde relevancia en favor de bienes intangibles (experienciales y potencialmente infinitos en cuanto a su consumo por parte del turista), y con su decadencia pierde relevancia también toda la normatividad consuetudinaria. Para ello, consideramos que el 'bien común' que es consumido en el postindustrialismo, y el que pueden gestionar las comunidades de forma inmanente, es su patrimonio, formas de vida y paisaje - ahora sí, entendido como una realidad estética consumida por la mirada del foráneo-y que, por tanto, deben reapropiarse la gestión patrimonial y los beneficios económicos de la misma. El primer gran reto fue abordar el actual marco jurídico que solamente contempla una gestión vertical y unidireccional de los recursos patrimoniales, según formas de gobierno dirigidas por una suerte de "tecnocracia". Ante la imposibilidad de llegar a un acuerdo sobre legislación con la administración, nos planteamos formas de gestión alternativas del patrimonio (eclesiástico y estatal) como bien común (Fernández Fernández, Alonso González, y Navajas Corral 2015). No sólo por una cuestión sociopolítica, sino porque consideramos que es también la mejor forma de preservar el patrimonio.

Esta reflexión deriva de una experiencia práctica previa. Así, desde 2005, un primer enfoque implicó colaborar con los proyectos europeos LEADER de financiación del desarrollo, planteando un proyecto denominado Parque Cultural Camín Real de la Mesa (Fernández Mier y Díaz López 2006). En él, se planteaba una forma innovadora de gestión basada en la valorización del paisaje de una zona rural amplia, enraizado en las formas de vida locales a partir de una vinculación estrecha entre comunidades e investigación arqueológica y agropecuaria. Pese a que el proyecto ganó el concurso público, nunca llegó a ser implementado por el grupo LEADER a cargo, que prefirió mantener un modelo desarrollista, neoliberal y centrado en la construcción de infraestructuras turísticas ajenas a las comunidades. Esto a la vez permitía al ente tecnocrático reproducir sus redes clientelares, un patrón socioeconómico generalizado en España que hemos diseccionado antropológicamente en otros trabajos (Alonso González y Macías Vázquez 2014b). Ante esta situación, varios miembros del grupo plantean desde 2011 un modelo construido a la inversa, de abajo arriba y no solucionista, sino problematizador, apoyándose en dos ideas principales. Por un lado, había que diseñar un sistema de gestión donde se hibridasen ciencia, economía y comunidad. Por otro, partir de la idea de que el patrimonio es un bien común y como tal ha de ser gobernado, dando cabida a la creación de nuevas subjetividades y diferentes tipos de comunidades patrimoniales con capacidad de autogestión y crítica, que no solamente amplifiquen el campo de los procesos de patrimonialización, sino que se constituyan como la vía más efectiva para la preservación de determinados "patrimonios" que perviven más allá del discurso académico-político autorizado. Para activar estas ideas pusimos en marcha un laboratorio experimental de innovación social y patrimonial que denominamos La Ponte-Ecomuséu, dotado de su propia personalidad jurídica (empresa social), basado en el principio de la autogestión comunitaria, en el que se integraron tanto expertos como amateurs, todos habitantes locales, y radicado en uno de los territorios donde trabajamos: Santo

\footnotetext{
${ }^{6}$ Web: http://www.laponte.org/; Documental: https://goo.gl/4ohROa
} 
Adriano ${ }^{6}$. De esta forma creamos una primera herramienta, un prototipo, que denominamos "empresa social del conocimiento", con la que se intenta acomodar actividad económica, dimensión social, cultural y política (Fernández Fernández, Alonso González, y Navajas Corral 2015; Navajas Corral y Fernández Fernández, 2017.)

Al querer implantar un órgano de gobernanza del patrimonio desde una organización civil y local, el primer gran reto al que nos enfrentamos fue abordar el actual marco jurídico que solamente contempla una gestión vertical y unidireccional de los recursos patrimoniales, según formas de gobierno dirigidas por una "tecnocracia" que no suele estar acostumbrada al tipo de reivindicaciones que se les plantearon (p. ej. impulsar modelos de co-gestión entre administración y comunidades locales de determinados bienes declarados de Interés Cultural con arte rupestre: vid. Fernández Fernández, Pérez Maestro y López Gómez 2015). Es algo natural y asumido crear partenariados público privados para la gestión de recursos colectivos como el agua, la recogida de basuras, etc. Sin embargo, plantear la existencia de un partenariado público-comunitario parece constituir en sí mismo un acto de subversión política con difícil encaje jurídico. No está implantada la idea de que existen vías alternativas a la gestión públicoprivada de los recursos comunes. Teniendo en cuenta la escasa posibilidad de transformar esa realidad jurídica y esa visión a corto plazo nos planteamos una estrategia basada en el establecimiento de relaciones y acuerdos con los diferentes titulares de los bienes patrimoniales, de esta forma no alteramos las relaciones de propiedad, pero sí creamos una herramienta mancomunada para su gobernanza y los gestionamos como si fuesen bienes comunes (Alonso González y Fernández Fernández 2013; Alonso González, Macías Vázquez y Fernández Fernández, 2016). Conviene matizar que nos orientamos por nuestro modelo tradicional de gestión de los comunes, coincidente con la idea de Ostrom (1990) de que no son en absoluto recursos abiertos, sino bienes gobernados por una comunidad local. Este error de concepción proviene precisamente de quienes nunca han entendido qué son los bienes comunes y cómo se gestionan, siguiendo la línea de Hardin (1968, para una crítica de esta concepción, ver Macías Vázquez y Alonso González 2016).

El principal resultado del Ecomuséu, más allá de esta reconexión identitaria y económica entre los habitantes locales, su paisaje y su patrimonio, es no aceptar resignificaciones simbólicas impuestas y construir narrativas alternativas a esta visión mercantilizadora de los recursos y de la propia identidad local, además de haberse constituido en un ámbito jurídico delimitado, que ha obligado al establecimiento de relaciones formales entre administración y comunidad local y la creación de toda una serie de documentos, proyectos, solicitudes, resoluciones, autorizaciones, etc., que en sí mismos constituyen un ámbito de innovación jurídica que puede resultar útil para replicar estos procesos en otros territorios (Fernández Fernández, Alonso González, y Navajas Corral 2015; Fernández Fernández, Pérez Maestro y López Gómez 2015). Este modelo se sitúa por tanto fuera del paradigma neoliberal del emprendedor LEADER y fuera del sistema asistencialista de las fundaciones medioambientales. Sin embargo, la limitación al ámbito local evidencia la necesidad de políticas más amplias de comunalización y gestión del paisaje que promuevan transformaciones similares a nivel, al menos, regional. Desde el grupo ha surgido esta necesidad de mirar más allá del propio territorio y se han impulsado proyectos como HESIOD (www.hesiod. eu), específicamente orientado a identificar y analizar experiencias similares y modelos de gobernanza alternativos en el campo del patrimonio cultural que nos sirvan como espacio de comparación, contraste y autocrítica (Fernández Fernández, 2016). El marco teórico es la innovación social, con lo que nos apropiamos también de términos de los que se han adueñado las ciencias puras y la empresa para anclarlos a las humanidades dotándolos de un nuevo sentido. Una batalla conceptual que nos parece muy necesaria: las tecnologías, las economías, las innovaciones, también son sociales y pueden ser activadas, pensadas y diseñadas desde el ámbito del humanismo y las ciencias sociales como la historia, la arqueología o la antropología. Por último, este proyecto está liderado por arqueólogos locales, que se implican a un nivel indisciplinar, tarea sin la cual el futuro de la arqueología como ciencia social y su autoridad epistémica entre el público resulta más que incierta. [Figura 4].

\section{CONCLUSIONES}

Este artículo ha presentado una reflexión alrededor del 'más allá' de la arqueología, que, por el contrario, creemos que debería pasar a formar parte habitual de reflexión 'interna' de la disciplina. El proceso de modernización capitalista tiende a despoblar el campo y fragmentar la relación inmanente del paisaje, en la acepción que hemos defendido aquí. Pese a que conceptos como urbano o rural, y también paisaje, tiendan a ser deconstruidos por las disciplinas académicas, estos siguen jugando un papel fundamental en la estructuración y percepción de las vidas de las personas en el contexto asturiano. Por ello debemos adaptar el concepto de paisaje a los nuevos tiempos, en los que la articulación de las relaciones entre personas y territorios no se restringe a lo local, sino que se estructura a una escala más amplia y dinámica. La arqueología juega un papel clave en el mantenimiento de la inmanencia de las personas con sus paisajes, tanto disciplinar como indisciplinarmente. La solución a los problemas del campo no es una mera arqueología pública, restringida a un público que observa y escucha, o de comunidad, restringida a una minoría local, generalmente más preocupada por otras cuestiones que por un discurso abstracto sobre el patrimonio que resulta generalmente extraño. Proponemos por ello, de forma no restrictiva 


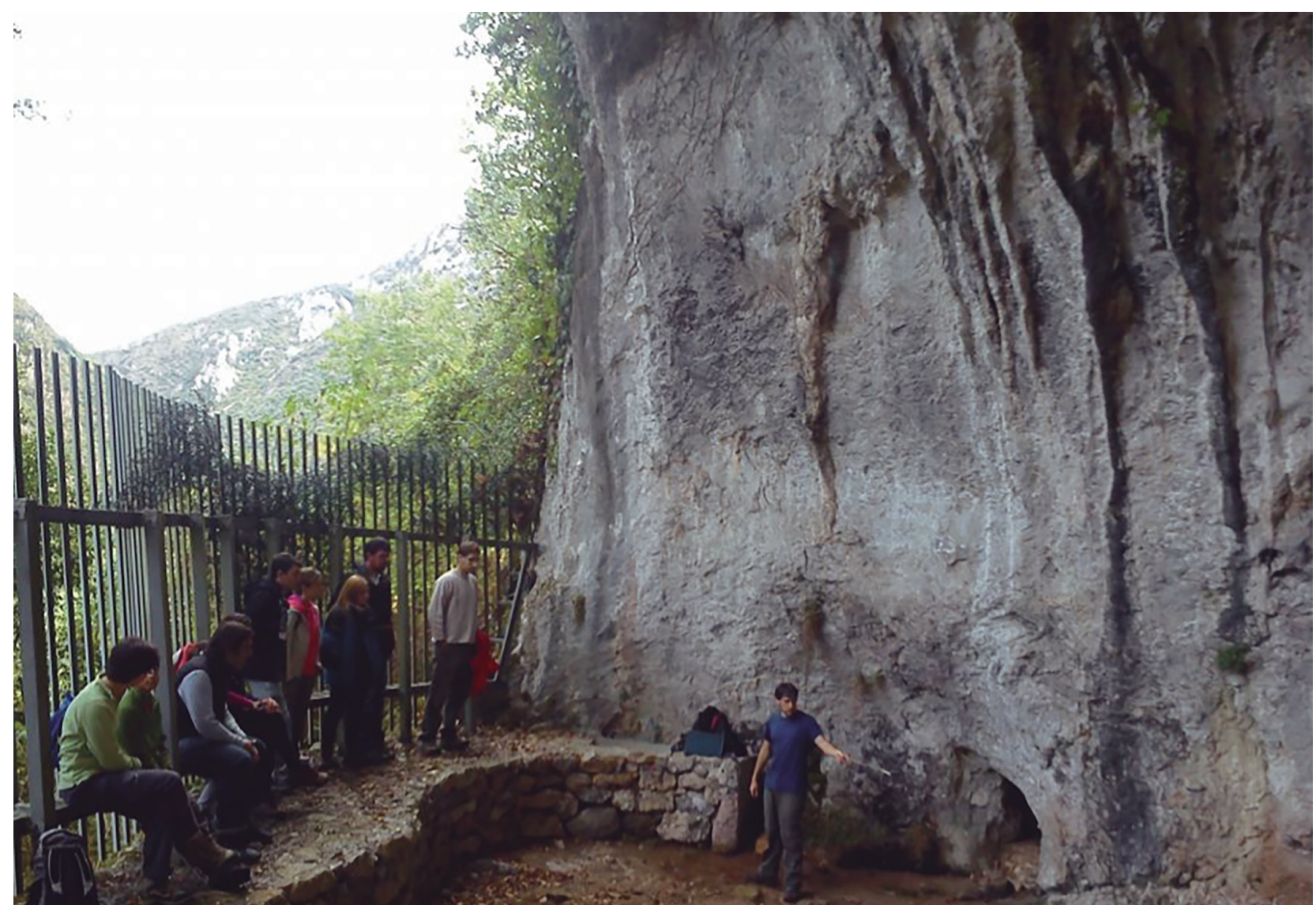

Fig. 4. Labor de difusión patrimonial de un miembro del Ecomuséu La Ponte en Villanueva. / Heritage outreach tasks carried out by a member of the Ecomuseum La Ponte in Villanueva.

y abierta a debate, la arqueología agraria, como una herramienta práctica y teórica que permita trazar genealogías del pasado y darles un uso en el presente, ayudando a la transformación de las relaciones en las que se insertan los grupos sociales que, y con los que, estudiamos. La arqueología puede así dar historicidad a las luchas y a la resiliencia de los grupos humanos, mostrar alternativas sociales en el pasado, y evidenciar las distintas formas que toman hoy las desigualdades socioeconómicas, y plantear modelos alternativos y experimentales de gobernanza del patrimonio. Para ello, resulta elemental luchar contra la ambivalencia del paisaje, y su paso de ser una red de relaciones inmanentes, a convertirse en una mercancía o bien de consumo cosificado en el que convergen tanto la mirada romántica exotizante, como la mirada racional que planifica esa exotización y su ulterior mercantilización.

\section{AGRADECIMIENTOS}

Este trabajo se enmarca en el proyecto de investigación ELCOS, Espacio locales y complejidad social. Las raíces medievales de un problema del siglo XXI, HAR2016-76094-C4-1-R, financiado por el Ministerio de Ciencia e Innovación.

\section{BIBLIOGRAFÍA}

Addison, J., 1958[1712]. The spectator. G. Smith. Dent \& Sons, London.

Alonso González, P., 2012. Flanqueando el procesualismo y post-procesualismo: Arqueología, teoría de la complejidad y la filosofía de Gilles Deleuze. Complutum 23(2), 13-32.

Alonso González, P., 2013a. "Arqueología Agraria: la formación de los paisajes en el Noroeste Peninsular." Disponible en: https://goo.gl/4C78xi.

Alonso González, P., 2013b. Cultural Parks and National Heritage Areas: Assembling Cultural Heritage, Development and Spatial Planning. Newcastle upon Tyne. Cambridge Scholars Publishing.

Alonso González, P., 2014a. From a given to a construct: Heritage as a commons. Cultural Studies 28(3), 359-390.

Alonso González, P., 2014b. La transición al post-productivismo: parques patrimoniales, parques culturales y ordenación territorial. EURE 40, 217-238.

Alonso González, P., 2016. Between Certainty and Trust: Boundary-Work and the Construction of Archaeological Epistemic Authority. Cultural Sociology 10 (4), 483 - 501.

Alonso González, P., 2017. El Antipatrimonio: Fetichismo y dominación en Maragatería (España). Madrid, CSIC. 
Alonso González, P., Fernández Fernández, J., 2013. Rural Development and Heritage Commons Management in Asturias (Spain): The Ecomuseum of Santo Adriano. Journal of Settlements and Spatial Planning 2, 245-253.

Alonso González, P. Macías Vázquez, A., 2014a. Bombardeando patrimonio en el Campo Militar de Tiro del Teleno (León): de la sublimación de la naturaleza a la construcción social del patrimonio cultural. Arbor 190(766), 1-10

Alonso González, P., Macías Vázquez, A., 2014b. Neoliberalismo corporativo y clientelismo en España: etnografía de la financiación europea del desarrollo rural a través de un proyecto fallido. AIBR 9(3), 223 - 250

Alonso González, P., Macías Vázquez, A., Fernández Fernández, J., 2016. Governance Structures for the Heritage Commons: La Ponte-Ecomuséu-Ecomuseum of Santo Adriano, Spain. In: Collision or Collaboration. Archaeology Encounters Economic Development, 153-170. Springer.

Angelo, D., 2010. Espacios indiscretos: reposicionando la mesa de la arqueología académica. In Pueblos Indígenas y Arqueología en América Latina, edited by Cristóbal Gnecco y Patricia Ayala, 161-187. CESO, Bogotá.

Ayala, P., Avendaño, S., Bahamondes, M., Cárdenas, U., Romero, A., 2003. Comentarios y discusiones en el encuentro "Reflexión sobre patrimonio cultural, comunidades indígenas y arqueología". Chungara 35(2), 379-409.

Ayán Vila, X.M., Gago Mariño, M., 2012. Herdeiros pola forza: patrimonio cultural, poder e sociedade na Galicia do século XXI. A Coruña, 2.0.

Barrell, J., 1980. The dark side of the landscape: The rural poor in English painting 1730-1840. Cambridge University Press, Cambridge.

Baxandall, M., 1988. Painting and experience in fifteenth century Italy: a primer in the social history of pictorial style. Oxford University Press, Oxford, New York.

Bender, B., 2006. Place and landscape. In: Tilley, C. (ed.), Handbook of material culture, 303-14. Thousand Oaks, SAGE, London.

Berque, A., 1997. En el origen del paisaje. Revista de Occidente 189, 7-21.

Butzer, Karl W., 1982. Archaeology as human ecology: method and theory for a contextual approach. Cambridge University Press.

Clarke, D., 1977. Spatial archaeology. Academic Press, London, New York.

Cosgrove, D., 1985. Social Formation and Symbolic Landscape. Barnes \& Noble, Madison.

Cosgrove, D., 2006. Modernity, community and the landscape idea. Journal of material culture 11(1-2), 49-66.

Criado-Boado, F., 2001. La memoria y su huella. Sobre arqueología, patrimonio e identidad. Claves de Razón Práctica $115,36-43$

Cruickshank, J. A., 2009. A play for rurality-Modernization versus local autonomy. Journal of Rural Studies 25(1), 98-107.

Chouquer, G., 2000. L'étude des paysages: essais sur leurs formes et leur histoire. Editions Errance, Paris.

Daniels, S., 2014. Marxism, culture and the duplicity of landscape. In: Peet, R., Thrift, N. (ed.), New models in geography, 196-220. Routledge, New York.
Daugstad, K., Fernández Mier, M., Peña-Chocarro, L., 2014. Landscapes of transhumance in Norway and Spain: Farmers' practices, perceptions, and value orientations. Norwegian Journal of Geography 68(4), 248-258.

Dematteis, G., 1985. Le metafore della terra: la geografia umana tra mito e scienza. Feltrinelli, Milano.

Diaz-Andreu, M., Champion, T., 1996. Nationalism and archaeology in Europe. Wesview Press, Boulder.

Durán, J. M., 2008. Hacia una crítica de la economía política del arte. Plaza y Valdés, Madrid.

English, P. W., Mayfield, Robert C., 1972. Man, Space, and Environment. Oxford University Press, London, New York.

Fabian, J., 2002. Time and the other: How anthropology makes its object. Columbia University Press, New York.

Fernández Fernández, J., 2016. Proyecto HESIOD. Definiendo e identificando ecosistemas de innovación social-patrimonial. PH. Boletín del Instituto Andaluz del Patrimonio Histórico 90, 236-239.

Fernández Fernández, J., 2017. Arqueología de una aldea medieval y su espacio agrario: Villanueva de Santo Adriano (Asturias, noroeste de la península Ibérica). Historia Agraria 72, 69-106.

Fernández Fernández, J., Alonso González, p., Navajas Corral, O., 2015. La Ponte-Ecomuséu: una herramienta de desarrollo rural basada en la socialización del patrimonio cultural. La Descommunal 1(2), 117-130

Fernández Fernández, J., Pérez Maestro, C., López Gómez, P., 2015. La interpretación del patrimonio como herramienta para la comunicación e innovación social en la gestión del arte rupestre. In: Collado Giraldo H., García Arranz, J.J. (Eds.), XIX International Rock Art Conference. Symbols in the Landscape: Rock Art and its Context, 1811-1825. Serie Arkeos 37

Fernández Mier, M., Díaz López, E., 2006. El Parque Cultural del Camín Real de la Mesa. In: Jean Paul Morel, Jordi Treserras, Juan Carlos Matamala (eds.), The Archaeology of crop fields and garden, 313-322. EDIPuglia, Bari.

Fernández Mier, M., Alonso González, P., 2016. Medieval north-west Spain: What can agrarian archaeology tell us about living rural landscapes? In: Ruralia X: Agrarian technology in the medieval landscape, edited by Jan Klápště, 291-308. Brepols, Turnhout.

Fernández Mier, M., Aparicio Martínez, P., González Álvarez, D., Fernández Fernández, J., Alonso González, P., 2013. Proyecto de Investigación: La formación de los paisajes agrarios del Noroeste peninsular durante la Edad Media (siglos $\mathrm{V}$ al XII). Debates de Arqueología Medieval 3, 359-374.

Fernández Mier, M., Fernández Fernández, J., Alonso González, P., López Sáez, J. A., Pérez Díaz, S., Hernández Beloqui, B., 2014. The investigation of currently inhabited villages of medieval origin: Agrarian archaeology in Asturias (Spain). Quaternary International 346, 41-55.

Fernández Mier, M., López Gómez, P., González Álvarez, D., 2013. Prácticas ganaderas en la Cordillera Cantábrica. Aproximación multidisciplinar al estudio de las áreas de pasto en la Edad Media. Debates de Arqueología Medieval 3, 167-220.

Garo, I., 2013. L'or des images: art, monnaie, capital. Ville brûle, Montreuil.

Ariño Gil, E., Gurt Esparraguera, J. M., Palet Martínez, J.M., 2004. El pasado presente: arqueología de los paisajes en la Hispania romana. Vol. 122. Universitat Barcelona. 
Gnecco, C., 2005. Ampliación del campo de batalla. Revista Textos Antropológicos 15(2), 183-195.

González Álvarez, D., Alonso González, P., 2014. De la representación cultural de la otredad a la materialización de la diferencia: Arqueología contemporánea de la domesticidad entre los vaqueiros d'alzada y los maragatos (España). Chungara, Revista de Antropología Chilena 46(4), 607-623.

Gosden, Ch., Head, L., 1994. Landscapea usefully ambiguous concept. Archaeology in Oceania 29(3), 113-116.

Guilaine, J., 1991. Pour une archéologie agraire: à la croisée des sciences de l'homme et de la nature. Armand Colin, Paris.

Haber, A., 2011. Nometodología Payanesa: Notas de metodología indisciplinada (con comentarios de Henry Tantalean, Francisco Gil García y Dante Angelo). Revista Chilena de Antropología 23 (1er semester), 9-49. doi:10.5354/07191472.2011.15564.

Hardin, G., 1968. The tragedy of the commons. American Association for the Advancement of Science, New York.

Ignateva, M. F., 2001. Los orígenes de la ciencia del paisaje en la geografía rusa. Scripta Nova 5, 79-104.

Inglehart, R., 2006. Modernización y posmodernización. CIS, Madrid.

Ingold, T., 1993. The temporality of the landscape. World archaeology 25(2), 152-174.

Izquierdo Vallina, J., 2008. Asturias, región agropolitana: las relaciones campo-ciudad en la sociedad posindustrial. KRK, Oviedo.

Lahiri, N., Shepherd, N., Watkins, J., Zimmerman, L., 2007. Diálogos desde el sur. Foro Virtual: arqueología y descolonización. Arqueología Suramericana 3(1), 3-19.

Lana Berasain, J. M., 2008. From equilibrium to equity. The survival of the commons in the Ebro Basin: Navarra from the 15th to the 20th centuries. International Journal of the Commons 2(2), 162-191.

Latour, B., 2008. Reensamblar lo social: una introducción a la teoría del actor-red. Manantial, Buenos Aires.

Lemaire, T., 1997. Archaeology between the invention and the destruction of the landscape. Archaeological Dialogues 4(1), 5-21.

Londoño, W., 2013. Tres momentos de la escritura antropológica en Colombia: notas para una discusión. Antípoda 16, 181-211.

Lowenthal, D., 1986. The past is a foreign country. Cambridge University Press, Cambridge.

Macías Vazquez, A., Alonso González, P., 2016. Knowledge Economy and the Commons: A Theoretical and Political Approach to Postneoliberal Common Governance. Review of Radical Political Economics 48(1), 140-157.

Maderuelo, J., 2006. El paisaje: génesis de un concepto. Abada, Madrid.

Marín Suárez, C., y Parga Dans, E. 2017. Arqueologia de Gestão em Madrid: presos pelo modelo de especulação capitalista do território. Revista de Arqueologia 28 (2), 118-138.

Martínez de Pisón, E., 2002. Reflexiones sobre el paisaje. In: Ortega Cantero, N. (ed.), Estudios sobre historia del paisaje español, 13-26. Catarata, Madrid.
Olwig, Kenneth. 2002. Landscape, nature, and the body politic: from Britain's renaissance to America's new world. Madison, University of Wisconsin Press.

Ostrom, E. 1990. Governing the commons: The evolution of institutions for collective action. Cambridge, Cambridge University Press.

Rodríguez Bote, M.T., 2014. La visión estética del paisaje en la Baja Edad Media. Medievalismo 24, 371-397.

Ruiz-Ruiz, J. F., Martín Civantos, J.M., 2017. La gestión comunitaria del agua en la cara norte de Sierra Nevada: Acción colectiva y saberes etnoecológicos en los sistemas de riego de origen andalusí. E-rph: Revista electrónica de Patrimonio Histórico 20, 76-103.

SADEI, 2016. Datos Básicos de Asturias 2016. Gobierno de Asturias, Oviedo.

Sauer, C. O., 1925. The Morphology of landscape. University Press, Berkeley.

Shepherd, N., Gnecco, C., Haber, A.F., 2016. Arqueología y decolonialidad. Buenos Aires; Durham, Ediciones del Signo; Center for Global Studies and the Humanities, Duke University.

Tafuri, M., 1995. Sobre el Renacimiento: Principios, ciudades, arquitectos. Cátedra, Madrid.

Tilley, Ch. Y., 1994. A phenomenology of landscape: places, paths, and monuments, Explorations in anthropology. Providence, R.I., Berg, Oxford.

Van der Ploeg, J. D., 2008. The new peasantries: struggles for autonomy and sustainability in an era of empire and globalization, Earthscan/James \& James, London, Sterling, VA. 